\title{
Population Pharmacokinetics of Paracetamol Across the Human Age-Range From (Pre)term Neonates, Infants, Children to Adults
}

The Journal of Clinical Pharmacology $\mathrm{XX}(\mathrm{XX}) \mathrm{I}-\mathrm{II}$

(c) 2013, The American College of Clinical Pharmacology DOI: 10.1002/jcph.259

\author{
Chenguang Wang ${ }^{1,2}$, Karel Allegaert ${ }^{3}$, Dick Tibboel ${ }^{2}$, Meindert Danhof', \\ Caroline D. van der Marel ${ }^{4}$, Ron A.A. Mathot ${ }^{5}$, and Catherijne A.J. Knibbe ${ }^{1,6}$
}

\begin{abstract}
In order to characterize the variation in pharmacokinetics of paracetamol across the human age span, we performed a population pharmacokinetic analysis from preterm neonates to adults with specific focus on clearance. Concentration-time data obtained in 220 neonates (post-natal age I-76 days, gestational age 27-42 weeks), infants (0.1 I-1.33 yrs), children (2-7 yrs) and adults (19-34 yrs) were analyzed using NONMEM 7.2. In the covariate analysis, linear functions, power functions, and a power function with a bodyweight-dependent exponent were tested. Between preterm neonates and adults, linear bodyweight functions were identified for Q2, Q3, VI, V2, and V3, while for CL a power function with a bodyweight-dependent exponent $\mathrm{k}$ was identified $\left(\mathrm{CL}_{i}=\mathrm{CL}_{\mathrm{p}} \times(\mathrm{BW} / 70)^{\mathrm{k}}\right)$. The exponent $\mathrm{k}$ was found to decrease in a sigmoidal manner with bodyweight from $\mathrm{I} .2$ to 0.75 , with half the decrease in exponent reached at $12.2 \mathrm{~kg}$. No other covariates such as age were identified. A pharmacokinetic model for paracetamol characterizing changes in pharmacokinetic parameters across the pediatric age-range was developed. Clearance was found to change in a nonlinear manner with bodyweight. Based on the final model, dosing guidelines are proposed from preterm neonates to adolescents resulting in similar exposure across all age ranges.
\end{abstract}

\section{Keywords}

allometry, paracetamol, pharmacokinetics, clearance, pediatric

Paracetamol or acetaminophen is an antipyretic and analgesic agent widely used in both adult and pediatric populations. Typically, paracetamol is given to patients orally or rectally. ${ }^{1}$ More recently, an intravenous formulation of paracetamol has become available, which was approved for use in term neonates, children and adults in Europe, even though the USFDA only approved its use for the treatment of acute pain and fever in adults and children aged 2 years and older. While intravenous paracetamol is now being used regularly as an analgesic in neonates, children and adults, ${ }^{2,3}$ in the last few years, intravenous paracetamol in a dose as high as $60 \mathrm{mg} / \mathrm{kg}$ has also been proposed as an off-label treatment of patent ductus arteriosus in preterm neonates. ${ }^{4-6}$

To derive evidence based dosing guidelines for intravenous paracetamol across age ranges including preterm neonates, term neonates, and infants, information is needed on its pharmacokinetics. In the past, different pharmacokinetic models have been reported for paracetamol or its prodrug propacetamol after oral, rectal of intravenous administration in neonates, infants and/or children. $^{7-12}$ These models have however not yet been used to guide dosing in children of different ages, as the official label for pediatric intravenous paracetamol has not changed since these publications. This may be explained by the fact that all these studies used a bodyweight based $3 / 4$ allometric function combined with an age-based matura- tion function to describe changes in paracetamol clearance across the pediatric age range. ${ }^{7-12}$ These complex models may have reduced predictive value, because they use both bodyweight and age on the same parameter (ie, clearance) while these covariates are correlated. ${ }^{13,14}$ There is therefore a need for validated pediatric models that can be used to guide dosing, particularly in the youngest age range including preterm and term neonates.

\footnotetext{
'Division of Pharmacology, LACDR, Leiden University, Leiden, The Netherlands

${ }^{2}$ Erasmus MC Sophia Children's Hospital, Intensive Care and Department of Paediatric Intensive Care, Rotterdam, The Netherlands ${ }^{3}$ Department of Development and Regeneration, KU Leuven and Neonatal Intensive Care Unit, University Hospitals Leuven, Leuven, Belgium

${ }^{4}$ Department of Anesthesiology, Erasmus MC, Rotterdam, The Netherlands

${ }^{5}$ Departments of Hospital Pharmacy and Clinical Pharmacology, Academic Medical Centre, Amsterdam, The Netherlands ${ }^{6}$ Department of Clinical Pharmacy, St. Antonius Hospital, Nieuwegein, The Netherlands
}

Submitted for publication 2 July 2013; accepted 26 December 2013.

Corresponding Author:

Prof. Dr. Catherijne A.J. Knibbe, St. Antonius Hospital, Department of Clinical Pharmacy, P.O. Box 2500, 3430 EM Nieuwegein

Email: c.knibbe@antoniusziekenhuis.nl 
In this study, we aimed to develop and validate a pediatric population pharmacokinetic model for paracetamol on the basis of pharmacokinetic data from eight previously published paracetamol studies in preterm and term neonates, infants, children and adults. ${ }^{9,15-21}$ In the covariate analysis, linear functions, power functions, and a power function with a bodyweight dependent exponent ${ }^{22-}$ 25 were tested to capture changes in the different pharmacokinetic parameters across the pediatric age range. The results of the model were used to simulate dose scenarios in all pediatric subpopulations given a similar target exposure across age. ${ }^{26}$

\section{Methods}

\section{Subjects of the Original Studies}

A total of 220 subjects from eight previously published studies $^{9,15-21}$ on paracetamol pharmacokinetics were included in the current study, including neonates (1-76 days), infants ( $0.11-1.33$ years), children ( $2-7$ years), and adults (19-34 years). No data were available from children between 8 and 19 years of age. Detailed information on the studies is given below and summarized in Table 1 .

\section{Neonates $9,15,16$}

Study I: Single dose intravenous propacetamol in neonates ${ }^{15}$. Thirty preterm (gestational age 27-35 weeks) and term (gestational age 36-40 weeks) neonates aged 1 day and weighing $0.5-4 \mathrm{~kg}$, who received single dose of intravenous propacetamol, were included. Propacetamol dose was $20 \mathrm{mg} / \mathrm{kg}$ (10 mg/kg paracetamol) for the first 15 neonates and $40 \mathrm{mg} / \mathrm{kg}(20 \mathrm{mg} / \mathrm{kg}$ paracetamol) for the next 15 neonates. Propacetamol bolus infusion was prepared from a $1 \mathrm{~g}$ propacetamol (500 $\mathrm{mg}$ paracetamol) powder-containing vial diluted in $50 \mathrm{~mL}$ normal saline. Propacetamol was administered for minor, painful procedures (ie, insertion of peripheral arterial, venous, or central venous line, chest tube placement) or as adjuvant therapy when receiving opioids.

Study 2: Repeated dose intravenous propacetamol in neonates ${ }^{16}$. Eighteen preterm and term neonates aged 176 days (postconceptual age 27-42 weeks) and weighing $0.84-4 \mathrm{~kg}$, who received repeated doses of intravenous propacetamol, were included. The dosing regimen consisted of a loading dose $(20 \mathrm{mg} / \mathrm{kg}$ paracetamol $)$ with a maintenance dosing of $10 \mathrm{mg} / \mathrm{kg} / \mathrm{dose}$ every 12,8 , or 6 hours for extreme preterm, preterm, and term neonates, respectively. Propacetamol was prescribed based on a standardized pain evaluation and analgesic algorithm after surgery or during specific medical conditions.

Study 3: Repeated dose intravenous paracetamol in neonates 9 . Sixty preterm and term neonates aged 1-28 days and weighing $0.6-4.8 \mathrm{~kg}$, who received repeated dose intravenous paracetamol, were included. The dosing regimen consisted of a loading dose $(20 \mathrm{mg} / \mathrm{kg})$ followed by a maintenance dose of $5,7.5$, or $10 \mathrm{mg} / \mathrm{kg}$ every 6 hours for extremely preterm preterm $(<32$ weeks postmenstrual age), preterm (32-36 weeks postmenstrual age) and term neonates ( $>36$ weeks postmenstrual age), respectively. Indications for paracetamol administration were medical (traumatic delivery, necrotizing enterocolitis, prostaglandin E2 administration, fever) or surgical (eg, cardiac, thoracic, abdominal). Samples were collected in the first 48 hours after loading dose with a non-uniform non-sparse sampling scheme with a median (range) number of samples per individual of 7 (2-11).

\section{Infants 17,20}

Study 4: Repeated dose intravenous propacetamol and rectal paracetamol in infants ${ }^{17}$. Twenty-six infants aged $0.11-1.33$ years and weighing $7.5-12.2 \mathrm{~kg}$ after major craniofacial surgery were included in the current analysis. During surgery, all infants received a rectal loading dose of $40 \mathrm{mg} / \mathrm{kg}$ paracetamol 2 hours before anticipated extubation. On admittance to the pediatric surgical ICU, the children were randomized to receive either a 15 minutes intravenous infusion of $40 \mathrm{mg} / \mathrm{kg}$ propacetamol (12 subjects) or $20 \mathrm{mg} / \mathrm{kg}$ paracetamol rectally (14 subjects) every 6 hours. Propacetamol or paracetamol was administered for analgesia after craniofacial surgery.

Study 5: Repeated dose rectal acetaminophen in infants ${ }^{20}$. Nineteen rectally dosed infants, aged $0.67-1.25$ years and weighing $7.9-12.2 \mathrm{~kg}$, were included. These infants received approximately 2 hours before anticipated extubation a loading dose of acetaminophen $(40 \mathrm{mg} / \mathrm{kg})$ that was administered rectally. Two hours after arrival in the pediatric surgical ICU, $20-\mathrm{mg} / \mathrm{kg}$ acetaminophen was administered rectally at 6,12 , and 18 hours.

\section{Children}

Study 6: Repeated dose rectal acetaminophen in children $^{21}$. Twenty-nine children, aged 2-7 years and weighing $14-33 \mathrm{~kg}$, were administered with acetaminophen for analgesia after adenotonsillectomy. Patients received a loading dose of $40 \mathrm{mg} / \mathrm{kg}$ rectally which was and followed by a maintenance doses of $30 \mathrm{mg} / \mathrm{kg}$ rectally for every 8 hours. The loading dose and maintenance doses were calculated based on following weight class 14 $16,17-18,19-21,22-23,24-26,27-28,29-31$, and 32$33 \mathrm{~kg}$, resulting in corresponding loading doses of 600 , $700,800,900,1000,1100,1200$, or $1300 \mathrm{mg}$ and corresponding maintenance dose of 450, 525, 600, 675, $750,825,900$, or $975 \mathrm{mg}$, respectively.

\section{Adults $^{18,19}$}

Study 7: Intravenous infusion of propacetamol in healthy male adults ${ }^{18}$. Data from twelve healthy male 


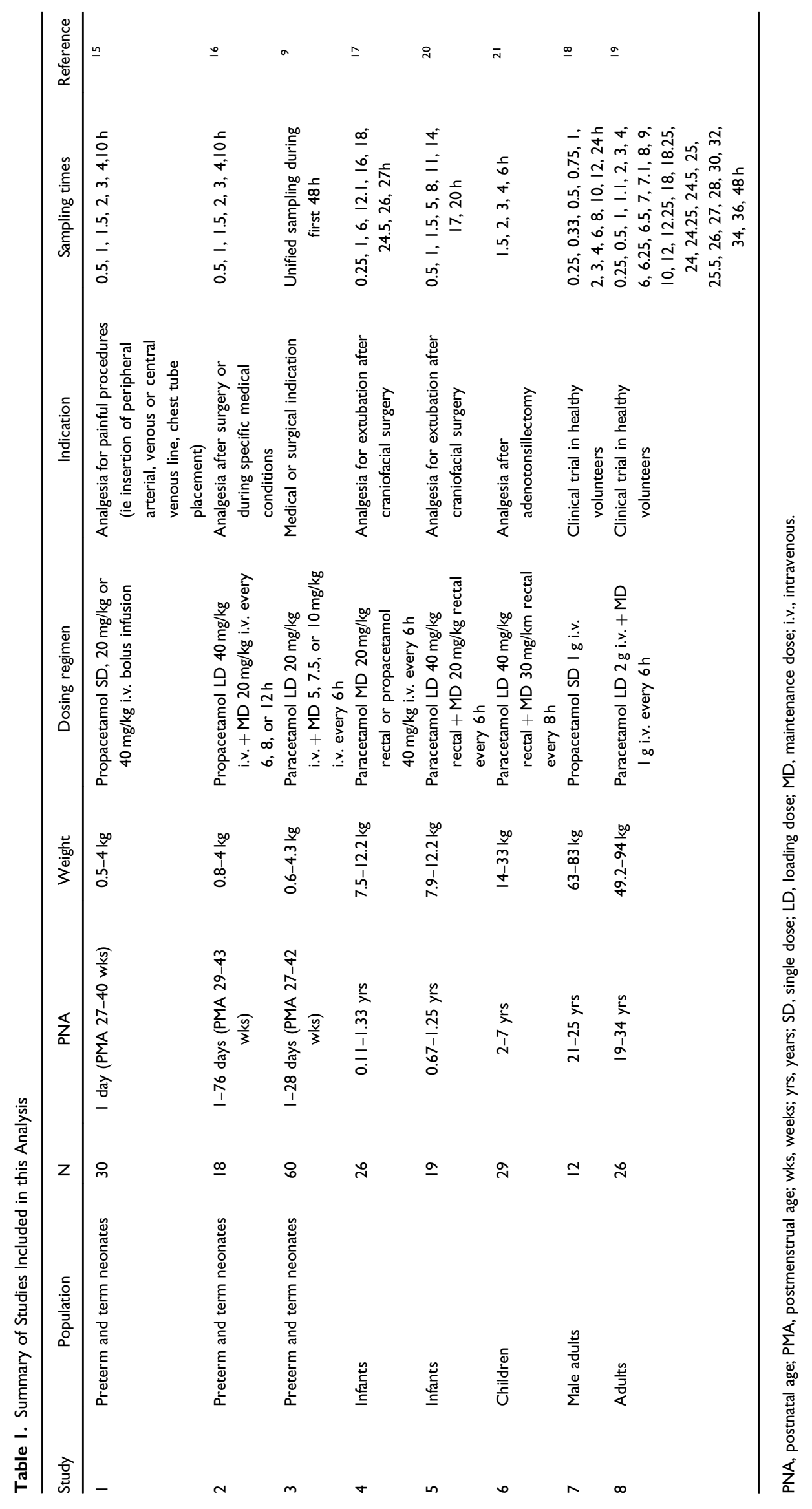


volunteers aged $21-25$ years and weighting $63-83 \mathrm{~kg}$ from one sub-branch (Study I, Occasion B) in the original study were included in the current analysis. Each subject was given $1 \mathrm{~g}$ of propacetamol $\mathrm{HCL}$ $(=500 \mathrm{mg}$ paracetamol) intravenously at a constant infusion rate over 15 minutes.

Study 8: Intravenous infusion of paracetamol in healthy adults ${ }^{19}$. Twenty-six healthy volunteers aged 19-34 years and weighing $49.2-94 \mathrm{~kg}$ were included in the current analysis. Each subject received first a 15 minutes infusion of $2 \mathrm{~g}$ of paracetamol (Perfalgan), followed by four additional 15 minutes infusions of $1 \mathrm{~g}$ paracetamol each, at 6 hours intervals.

\section{Pharmacokinetic Modeling}

Model building. The population pharmacokinetic analysis was performed with the non-linear mixed effects modeling software NONMEM version 7.2. (ICON Development Solutions, Ellicott City, MD) using the first-order conditional estimation method with the interaction (FOCEI). Pirana ${ }^{27}$ and R (version 2.15.1) were used to visualize the output and evaluate the models.

Paracetamol concentrations were logarithmically transformed and fitted simultaneously, since the range in concentrations was more than 1000 -fold. Model building was performed in four steps: (1) selection of structural model, (2) selection of statistical sub-model, (3) systematic covariate analysis, (4) model validation. For selection of a structural or statistical model, a difference in objective function (OFV) between models of more than 3.84 points was considered as statistically significant $(P<.05$ assuming a Chi-square distribution). Next to evaluation of the OFV for statistical significance, the goodness-of-fit plots (observed vs. individual predicted concentrations and vs. population predicted concentrations, and conditional weighted residuals vs. time and vs. population prediction concentrations) of all data and data stratified per age category were evaluated. Beside the OFV and goodness-of-fit plots, the total number of parameters, improvement of the individual concentrationtime profiles, the confidence intervals of the parameter estimates and the correlation matrix were assessed when selecting the structural model. For intravenously administered propacetamol (72 subjects), 1 unit propacetamol dose was converted to 0.5 unit of paracetamol as dosing input for the pharmacokinetic analysis.

Structural model. One, two, and three compartment models were tested. A three-compartment model for distribution and elimination of paracetamol, which was parameterized in terms of total clearance (CL), volume of distribution of the central compartment (V1), volume of distribution of the rapidly-equilibrating peripheral compartment (V2) and slowly-equilibrating peripheral compartment (V3), and inter-compartmental CL between central compartment and two peripheral compartments (Q2, Q3), was superior over a one compartment model given the criteria as described under Model building. To describe the process of rectal absorption for individuals who were given paracetamol rectally, a rectal deposit compartment was incorporated into the model with first-order absorption rate constant (Ka), bioavailability (F), and lag time (Tlag) as parameters.

For the pharmacokinetic data from studies in which propacetamol (an intravenous prodrug of paracetamol) was used, we tested a pseudo deposit compartment for propacetamol and its first order hydrolysis rate in order to describe the process of conversion from propacetamol to paracetamol. ${ }^{20}$ As the half-life of the hydrolysis rate turned out to be very short $(<0.0001$ hour), this pseudo deposit compartment was not implemented in the final model.

Statistical model. Interindividual variability in the pharmacokinetic parameters was tested in the model assuming log-normal distributions, expressed as

$$
\theta_{\mathrm{i}}=\theta_{\mathrm{TV}} \times e^{\eta_{\mathrm{i}}}, \eta_{\mathrm{i}} \sim \mathrm{N}\left(0, \omega^{2}\right)
$$

where $\theta_{i}$ is the individual pharmacokinetic parameter value for the ith individual, $\theta_{\mathrm{TV}}$ is the population pharmacokinetic parameter value or typical value, and $\eta_{i}$ is a random variable for the ith individual from a normal distribution with mean zero and variance $\omega^{2}$. In addition to testing of the inclusion of interindividual variability on individual parameters, model improvement by inclusion of covariance between these variability parameters was tested as well.

Absolute bioavailability was constrained between 0 and 1 , as it represents the ratio between the amount of drug reaching the systemic circulation and the amount of drug administered. ${ }^{28}$ Therefore, the interindividual variability in bioavailability could not be parameterized as described in Eq. (1) and was parameterized in a model proposed by Karlsson et $\mathrm{al}^{28}$ using the following function:

$$
F_{i}=\frac{e^{\ln \left(\frac{\mathrm{TVF}}{1-\mathrm{TVF}}\right)+\eta_{\mathrm{i}}}}{1+\mathrm{e}^{\ln \left(\frac{\mathrm{TVF}}{1-\mathrm{TVF}}\right)+\eta_{\mathrm{i}}}}
$$

For the residual error, an additive model for logtransformed concentrations was used, which was expressed as:

$$
\log \mathrm{C}_{\mathrm{ij}}=\log \mathrm{C}_{\text {pred }_{\mathrm{ij}}}+\varepsilon, \varepsilon \sim \mathrm{N}\left(0, \sigma^{2}\right)
$$

where $C_{i j}$ is the value of the observed paracetamol concentration of ith individual at time $j$, is the value of the predicted paracetamol concentration of the ith individual at time $\mathrm{j}$, and $\mathrm{C}_{\text {pred }_{\mathrm{ij}}}$ is a random variable for this 
observation from a normal distribution with mean zero and variance $\sigma^{2}$.

Covariate model. Covariates (bodyweight, age) were plotted independently versus the individual post hoc parameter estimates and the conditional weighted residuals to evaluate potential relationships. In addition, gestational age and postmenstrual age were evaluated for neonates. Potential covariates were separately implemented into the model using a linear function, power function or a power function with a bodyweight dependent exponent. This power function with a bodyweight dependent exponent is called a bodyweight dependent exponent (BDE) model ${ }^{22}$ and is shown in Eq. (4), where it is applied to paracetamol CL.

$\mathrm{Cl}_{\mathrm{i}}=\mathrm{Cl}_{\mathrm{p}} \times\left(\frac{\mathrm{BW}_{\mathrm{i}}}{70}\right)^{\mathrm{k}}, \mathrm{k}=\mathrm{k}_{0}-\frac{\mathrm{k}_{\max } \times \mathrm{BW}_{\mathrm{i}}^{\gamma}}{\mathrm{k}_{50}^{\gamma}+\mathrm{BW}_{\mathrm{i}}^{\gamma}}$

In Eq. (4), $\mathrm{Cl}_{\mathrm{i}}$ is clearance in the ith individual with bodyweight $\mathrm{BW}_{\mathrm{i}} ; \mathrm{Cl}_{\mathrm{p}}$ is the clearance in a standardized adult with a bodyweight of $70 \mathrm{~kg}$; $\mathrm{BW}_{\mathrm{i}}$ is bodyweight of an individual $\mathrm{i} ; \mathrm{k}$ is the exponent; $\mathrm{k}_{0}$ is the value of the exponent at a theoretical bodyweight of $0 \mathrm{~kg}$; $\mathrm{k}_{\max }$ is the maximum decrease of the exponent; $\mathrm{k}_{50}$ is the bodyweight at which a $50 \%$ decrease in the maximum decrease of exponent value is attained, and $\gamma$ is the Hill coefficient determining the steepness of sigmoidal decline in the exponent. $^{22}$

The significance of a covariate for a parameter in the model was statistically evaluated by the use of the OFV. In the forward inclusion a $P$ value $<.005$ was considered as statistically significant while a more stringent $P$ value $<.001$ was used in the backward deletion. When two or more covariates were found to significantly improve the model, the covariate that reduces the OFV the most was retained in the model. Then the influence of the remaining covariates was tested in the covariate-adjusted model for significance. The final covariate model was selected on the basis of the criteria in this section covariate analysis, provided that improvements as a result of inclusion of the covariate in the model were observed as described under Model Building. Finally, the model was accepted when the results of the model validation were adequate (see under Model validation).

\section{Model Validation}

The model was validated internally using five criteria that were recently proposed for pediatric population model evaluation. ${ }^{29}$ (i) The coefficient of variation (CV) of the parameter estimates either from the covariance step in NONMEM or from 200 stratified bootstrap resampling results is less than $50 \%$, (ii) The basic diagnostic plots and particularly the plots of the observed versus population predicted concentrations stratified for age, are visually assessed for bias and precision, (iii) The $\eta$-shrinkage is calculated and evaluated according to Karlsson and Savic, ${ }^{30}$ (iv) The individual and population predicted parameters are plotted against the primary covariate to evaluate whether the individual predicted parameters are equally distributed around the population predicted parameters, (v) The simulation based normalized prediction distribution error (NPDE) $)^{31}$ is calculated based on 2,000 simulations of the entire dataset and is evaluated visually for bias and precision. ${ }^{31}$

\section{Simulations on the basis of the final model}

Based on the final model paracetamol concentration-time profiles were simulated with NONMEM for children with a bodyweight of $0.5,1,1.5,2,3,5,8,9,15,20,35$, and $50 \mathrm{~kg}$. Two intravenous administration dosing regimens were simulated, that is, a standard of care dosing regimen and a model-based dosing regimen.

The standard of care dosing regimen for prematurely born neonates and children was based on the Dutch Children's Formulary $[5 \mathrm{mg} / \mathrm{kg}$ every 6 hours (group 1 with weight $0.5,1,1.5$, and $2 \mathrm{~kg}$ ) $]^{32}$ while for term neonates and children it was based on the official labeling information in the Netherlands (for term neonates and children weighing less than $10 \mathrm{~kg} 7.5 \mathrm{mg} / \mathrm{kg}$ every 6 hours (group 2 with weight 3,5,8, and $9 \mathrm{~kg}$ ) and for children weighing between 10 and $50 \mathrm{~kg} 15 \mathrm{mg} / \mathrm{kg}$ every 6 hours (group 3 with weight 15, 20, 35, and $50 \mathrm{~kg}$ ).

In the model-based dosing regimen, recommended doses were derived for children of all bodyweights on the basis of a loading dose and a maintenance dose every 6 hours. For this model based dosing regimen, an average target concentration was needed. Since the target therapeutic average paracetamol concentration for neonates is unknown and the 6-hourly $15 \mathrm{mg} / \mathrm{kg}$ dose is widely accepted for children weighing more than $10 \mathrm{~kg}$, we took the average paracetamol concentration reached in this dose group (ie, $9 \mathrm{mg} / \mathrm{L}$ ) as the target concentration for the model-based dosing regimen. On the basis of the $9 \mathrm{mg} /$ $\mathrm{L}$ concentration as the target concentration, loading doses, and maintenance doses of intravenous paracetamol were optimized based on CL and volume of distribution as estimated using the final model.

\section{Results}

For the analysis, data of 220 subjects varying from preterm and term neonates, infants, children, and adults receiving paracetamol intravenously or rectally or propacetamol intravenously were available. An overview of the data of eight paracetamol studies was summarized in Table 1.

Table 2 presents the results of the final model. The results demonstrated that a three-compartment structural model for distribution and elimination of paracetamol was 
Table 2. Parameter Estimates of the Final Model

\begin{tabular}{|c|c|c|c|c|}
\hline Parameter & Model estimates & RSE & Bootstrap mean & Bootstrap RSE \\
\hline \multicolumn{5}{|l|}{ Fixed effect } \\
\hline $\mathrm{CL}$ & $=\mathrm{TVCL} \times(\mathrm{BW} / 70)^{\mathrm{k}}$ & & & \\
\hline TVCL $(\mathrm{L} / \mathrm{h} \times 70 \mathrm{~kg})$ & 17.6 & $3.2 \%$ & 17.5 & $2.8 \%$ \\
\hline k & $=\mathrm{k}_{0}-\mathrm{k}_{\max } \mathrm{BW} \mathrm{W}^{\gamma} /\left(\mathrm{k}_{50}{ }^{\gamma}+\mathrm{BW}^{\gamma}\right)$ & & & \\
\hline$k_{\max }$ & 0.45 & $5.4 \%$ & 0.44 & $5.7 \%$ \\
\hline $\mathrm{k}_{0}-\mathrm{k}_{\max } \S$ & $0.75 \mathrm{FIX}$ & - & - & - \\
\hline $\mathrm{k}_{50}(\mathrm{~kg})$ & 12.2 & $27.2 \%$ & 28.3 & $202.9 \%$ \\
\hline$\gamma$ & I.4 FIX & - & - & - \\
\hline VI & $=\mathrm{TVVI} \times(\mathrm{BW} / 70)$ & & & \\
\hline TVVI (L/70 kg) & 25.1 & $11.2 \%$ & 24.4 & $16.1 \%$ \\
\hline Q2 & $=\mathrm{TVQ} 2 \times(\mathrm{BW} / 70)$ & & & \\
\hline TVQ2 (L/h × 70 kg) & 96.8 & $12.6 \%$ & 103.7 & $19.5 \%$ \\
\hline V2 & $=\mathrm{TVV} 2 \times(\mathrm{BW} / 70)$ & & & \\
\hline TVV2 (L/70 kg) & 36.1 & $5.5 \%$ & 36.8 & $7.3 \%$ \\
\hline Q3 & $=\mathrm{TVQ} 3 \times(\mathrm{BW} / 70)$ & & & \\
\hline TVQ3 $(\mathrm{L} / \mathrm{h} \times 70 \mathrm{~kg})$ & 1.4 & $9.8 \%$ & 1.4 & $8.1 \%$ \\
\hline V3 & $=\mathrm{TVV} 3 \times(\mathrm{BW} / 70)$ & & & \\
\hline TVV3 (L/70 kg) & 21.6 & $12.8 \%$ & 22.2 & $13.9 \%$ \\
\hline $\mathrm{Ka}(1 / h)$ & 0.25 & $13.8 \%$ & 0.29 & $25.9 \%$ \\
\hline Tlag (h) & 0.4 & $5.7 \%$ & 0.4 & $6.4 \%$ \\
\hline $\mathrm{F}$ & 0.96 & $8 \%$ & 0.9 & $11.7 \%$ \\
\hline \multicolumn{5}{|l|}{ Random effect (\%) } \\
\hline$\omega \mathrm{CL}$ & $35.4 \%$ & $9.1 \%$ & $34.6 \%$ & $17.6 \%$ \\
\hline$\omega \mathrm{VI}$ & $63.6 \%$ & $12.6 \%$ & $68.4 \%$ & $36.6 \%$ \\
\hline$\omega \mathrm{Ka}$ & $86.7 \%$ & $14 \%$ & $95.7 \%$ & $42.5 \%$ \\
\hline$\omega \mathrm{F}$ & $205.9 \%$ & $76.4 \%$ & $311 \%$ & $110 \%$ \\
\hline$\sigma$ & $21.4 \%$ & $8.8 \%$ & $21.4 \%$ & $15.9 \%$ \\
\hline
\end{tabular}

$\mathrm{k}$, bodyweight dependent exponent; $\mathrm{k}_{\max }$, maximum decrease of $\mathrm{k}$; $\mathrm{k}_{0}$, value of $\mathrm{k}$ at a theoretical bodyweight of $0 \mathrm{~kg}$; $\mathrm{k}_{50}$, the bodyweight at which a $50 \%$ decrease in the maximum decrease of $\mathrm{k}$ is attained; $\gamma$, the Hill coefficient determining the steepness of sigmoidal decline in $\mathrm{k}$; Ka, rectal absorption constant rate; Tlag, lag time in rectal absorption; $F$, rectal bioavailability; $\omega$, standard deviation of the inter-individual variability $(\eta)$; $\sigma$, standard deviation of the proportional residual error $(\varepsilon)$; $\S k_{0}-k_{\max }$ was parameterized as a fixed effect parameter (THETA) in NONMEM.

superior over a two-compartment model, based on the improvement of the goodness of fit plots and a decrease in OFV value $(P<.0001)$. The population lag time (Tlag) of the rectal dose was estimated to be 0.409 hour without interindividual variability. The rectal bioavailability was estimated to be 0.962 with a large interindividual variability of $205.9 \%$. The rectal absorption rate constant (Ka) was estimated to be $0.28(1 / \mathrm{h})$ with an interindividual variability of $86.7 \%$.

Concerning the covariate analysis, bodyweight was identified a significant covariate for all structural pharmacokinetic parameters except for Ka, F, and Tlag. For the parameters Q2, Q3, V1, V2, and V3, the influence of bodyweight was best described by a linear function (Table 2). For CL, a power function in which the exponent $\mathrm{k}$ varied with bodyweight in a sigmoidal function (BDE model, Eq. 4) proved superior over a linear or a power function with a fixed exponent $\mathrm{k}(P<.05)$ according to the criteria stated in section Methods. The bodyweightdependent exponent $\mathrm{k}$ was estimated to decrease from a value of $1.2\left(\mathrm{k}_{0}\right)$ at the theoretical bodyweight of zero kilogram to $0.75\left(\mathrm{k}_{0}-\mathrm{k}_{\max }\right)$ and reached half this decrease at 12.2 kilogram $\left(\mathrm{k}_{50}\right)$ (Table 2). The corresponding age to the bodyweight of $12.2 \mathrm{~kg}$ (k50) proved 2 years in this study. The minimum exponent $\left(\mathrm{k}_{0}-\mathrm{k}_{\max }\right)$ that is applicable to the adult range only was fixed to 0.75 , since this value for the exponent was identified in a separate pre-analysis based on adult data only. The Hill factor $(\gamma)$ was found to be 1.4 and was fixed to this value in the final model in order to get the covariance step (Table 2).

Figure 1 (left panel) shows that on the basis of this BDE model, the change in individual paracetamol CL over bodyweight of all individuals of this analysis was very well captured. As $\eta$-shrinkage was low (12.8\%), the reliability of the individual CL values in the subjects can be considered high. ${ }^{30}$ With respect to model validation, goodness of fit plots stratified by age (1. birth to 1 month; 2. 1 month to 2 years; 3 . 2-12 years; 4 . 12-16 years) showed that the population predicted paracetamol concentrations of the final model were in good agreement with the observed paracetamol concentrations for the different age ranges (Supplemental Figure S1). Concerning the evaluation of the implementation of the covariate model for $\mathrm{CL}$ in the final model by the bodyweight-dependent 

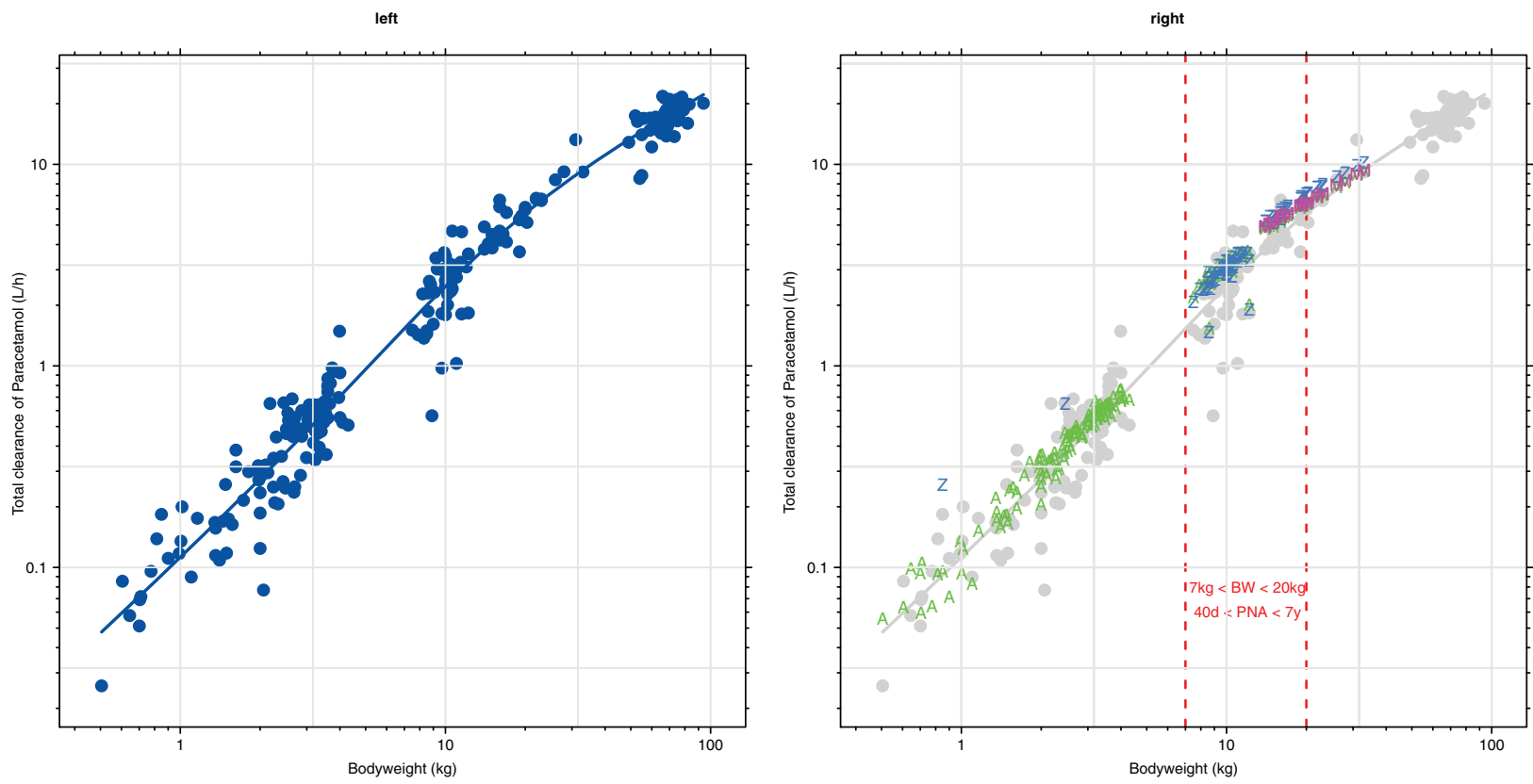

Figure I. Paracetamol clearance (filled circle) against bodyweight of all individuals in this study (left panel) and paracetamol clearance (filled circle) against bodyweight of all individuals in this study in comparison with the results of three previously reported models (letters) (right panel) in log-log scale. Solid line: model predicted paracetamol clearance as defined by $\mathrm{CL}_{i}=\mathrm{CL}_{\mathrm{p}} \times(\mathrm{BW} / 70)^{\mathrm{k}}$ with $\mathrm{k}=\mathrm{k}_{0}-\mathrm{k}_{\max } \mathrm{BW}^{\gamma} /\left(\mathrm{k}_{50}{ }^{\gamma}+\mathrm{BW}^{\gamma}\right)$ with parameters as shown in Table 2. Dashed vertical lines: boundary lines of a range in bodyweight between 7 and $20 \mathrm{~kg}$, which corresponds to a range in postnatal age (PNA) between 40 days and 7 years in our study dataset. "A": predicted clearance with model from Anderson et al " ; "Z": predicted clearance with model from Zuppa et al "; "M": predicted clearance with model from Mohammed et al. ${ }^{12}$

exponent (BDE) model, Supplemental Figure S2 shows that there were no remaining trends in the post hoc eta of CL versus bodyweight, postnatal age (PNA), postmenstrual age (PMA), and gestational age (GA) plots. As the data of PMA and GA were only available in neonates, corresponding plots were limited to 50 weeks in the $\mathrm{x}$ axes. As a simulation-based validation method, the normalized prediction distribution error (NPDE) showed that paracetamol concentrations in the models were normally distributed (mean $=-0.02462$, variance $=0.7756$, $P<.001$ ) around the median prediction and that there was no trend in the NPDE versus TIME and versus the logarithm of the individual predicted concentrations (Supplemental Figure S3). In addition, the results of the bootstrap validation of the final model are listed in Table 2.

Simulations on the basis of the final model for both a standard of care dosing regimen and a model-based dosing regimen are presented in Figure 2. For the standard of care dosing regimen, 3 different maintenance doses were used 6 hourly, that is, $5,7.5$, and $15 \mathrm{mg} / \mathrm{kg}$ for neonates with a body weight between $0.5-3,3-10$, and children with weight $10-50 \mathrm{~kg}$, respectively, according to the official label and the Dutch Childrens Formularium. ${ }^{32}$ The simulations upon the standard of care dosing regimen in group 3 (Figure 2a, bottom row, $10-50 \mathrm{~kg}$ ) show that on average a concentration of $9 \mathrm{mg} / \mathrm{L}$ was attained (Figure 2a, dotted reference line). For the other groups, a variety of average concentrations was attained upon this traditional $\mathrm{mg} / \mathrm{kg}$ dosing regimen (Figure $2 \mathrm{a}$, upper two rows).

Table 3 shows the loading and maintenance doses for the model-based dosing regimen aiming for a concentration of $9 \mathrm{mg} / \mathrm{L}$ in all groups with individuals varying in bodyweight between 0.5 and $50 \mathrm{~kg}$ (Figure $2 \mathrm{~b}$ ). Figure $2 \mathrm{~b}$ shows the simulated concentrations in all individuals upon this model-based dosing regimen. This figure illustrates that the target concentration of $9 \mathrm{mg} / \mathrm{L}$ is achieved at all weights when using the dosing table depicted in Table 3.

\section{Discussion}

In this meta-pharmacokinetic analysis we studied the pharmacokinetics of paracetamol using data from eight different clinical studies in (pre)term neonates, infants, children, and adults. The results showed that, developmental changes in CL were best described on the basis of a power function with an exponent that varied with bodyweight. This exponent was found to vary from the value of 1.2 for neonates to 0.75 for older children and adults. Using this function, the influence of bodyweight on CL was adequately implemented, as changes in CL with bodyweight were captured in an optimal way (Figure 1, left panel). This model was confirmed by advanced internal validation procedures that have been proposed 

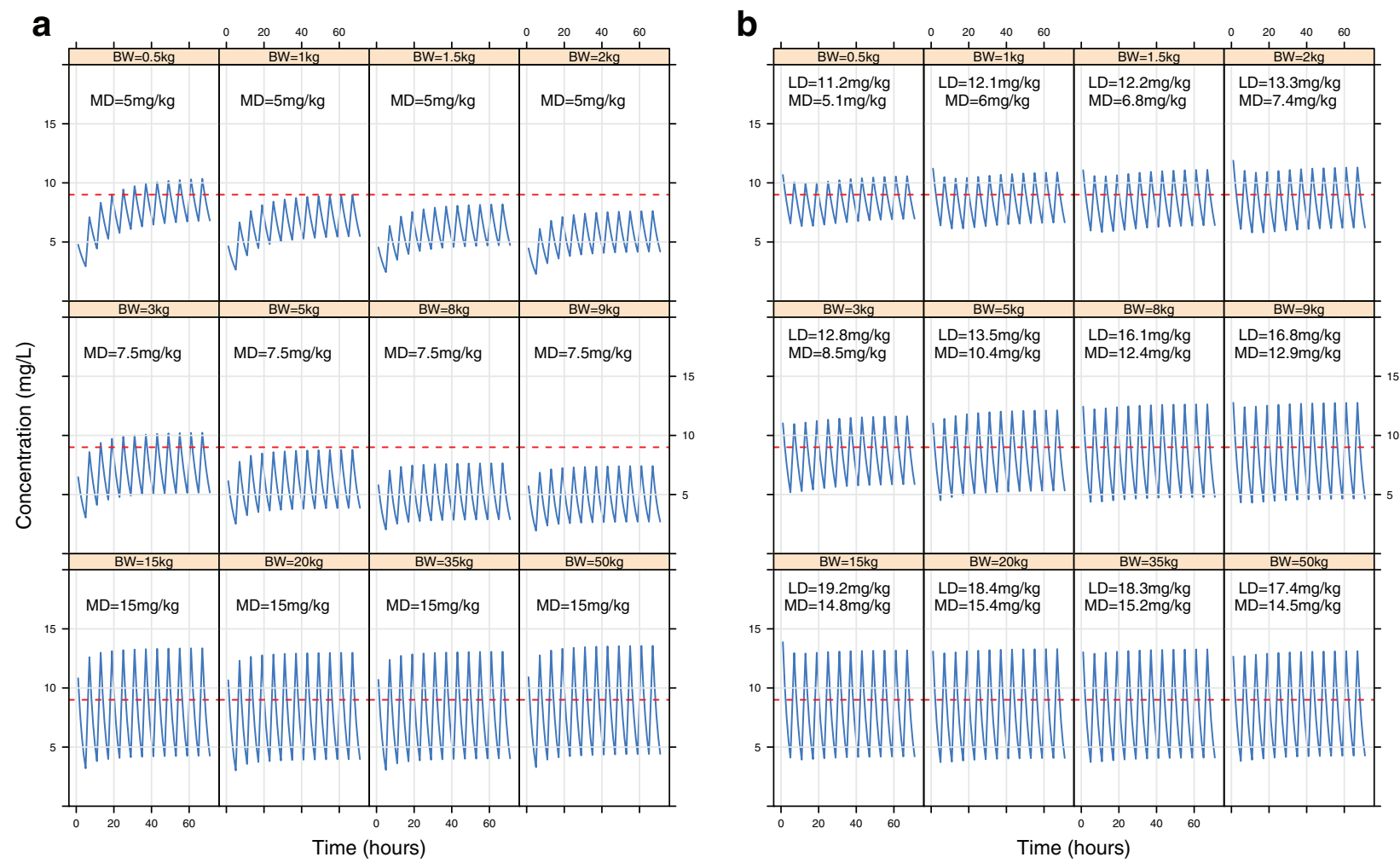

Figure 2. Simulated paracetamol concentration profiles of intravenously administered paracetamol 4 times daily based on a standard of care regimen as described in section Methods (panel a) and a final model optimized regimen (panel b, Table 3) for neonates with a body weight between 0.5 and $3 \mathrm{~kg}$ (upper row), neonates and infants weighing between 3 and $10 \mathrm{~kg}$ (middle row) and children with a weight between 10 and $50 \mathrm{~kg}$ (lower row). Solid curves are paracetamol concentration profiles; horizontal dotted line is the target average paracetamol concentration $(9 \mathrm{mg} / \mathrm{L})$ used for the final model optimized regimen (panel b) which was calculated from the average steady state concentration obtained upon the standard of care dosing regimen in individuals weighing $15,20,35,50 \mathrm{~kg}$ (panel a); MD is the maintenance dose per kilogram; LD is the loading dose per kilogram.

particularly for pediatric studies where datasets are often sparse and variability is large. ${ }^{29}$ Most importantly, Figure S2 shows that the model can be applied for individuals with a given bodyweight, age, PMA, or PNA because the Empirical Bayes Estimates (EBE) based post hoc interindividual variability of CL had no trend against either bodyweight or age (including PNA, PMA, and GA) (Figure S2), confirming that an appropriate final model has been reached. ${ }^{33}$ These results demonstrate that the influence of bodyweight on CL as described by the highly non-linear BDE function also captures the influence of age (PNA, PMA, or GA) into account. However, caution is needed for this BDE function in case of data from obese individuals. There were no obese individuals in our datasets, therefore our model may not be valid for obese children.

We compared our model with previously reported models for paracetamol CL in children as listed in Table 4. The model reported by Zuppa et $\mathrm{al}^{11}$ mainly studied children of $7 \mathrm{~kg}$ onwards without reporting bodyweight range. The model reported by Mohammed et $\mathrm{al}^{12}$ studied children from 1.8 years onwards and the model reported by Anderson et al also had access to data from a large number of preterm and term neonates. ${ }^{10}$ The modelpredicted paracetamol CL from these three models were derived by applying the respective maturation functions (Table 4) to the individual data in our analysis. The predictions were limited to the age range of the original studies (Table 4) in order to prevent unintended extrapolations of three literature models. In Figure 1 (right panel), we plotted the model predicted CL from the three previously published models ${ }^{10-12}$ and from our model, against the individual bodyweights of all our individuals. This figure shows that the predictions of these four models were in reasonable agreement with each other, although different functions and covariates were used. For the neonatal range, the performance of the Anderson's model $^{10}$ seemed in good agreement with the current model, even though the two models varied largely in functions and number of covariates (Table 4). For individuals aged between 40 days and 7 years with corresponding body weight between $7 \mathrm{~kg}$ and $20 \mathrm{~kg}$ (Figure 1 right panel), it seems that the models by Zuppa et al, ${ }^{11}$ by Anderson et $\mathrm{al},{ }^{10}$ and by Mohammed et al ${ }^{12}$ slightly overestimated CL compared to the estimates obtained in our study. 
Table 3. Model-Based Dosing Regimen of Intravenous Paracetamol Aiming for a Target Paracetamol Concentration of $9 \mathrm{mg} / \mathrm{L}$ in Individuals Weighing Between 0.5 and $50 \mathrm{~kg}$

\begin{tabular}{|c|c|c|c|c|c|c|c|c|c|c|c|c|}
\hline BW (kg) & $\mathrm{CL}(\mathrm{L} / \mathrm{h})$ & $\mathrm{V}(\mathrm{L})$ & t I/2 (h) & $\begin{array}{l}\text { Target Cavg } \\
\quad(\mathrm{mg} / \mathrm{L})\end{array}$ & $\begin{array}{l}\text { MD } \\
\text { (mg) }\end{array}$ & $\begin{array}{l}\mathrm{MD} / \mathrm{kg} \\
(\mathrm{mg} / \mathrm{kg})\end{array}$ & $\begin{array}{l}\text { SoCMD/kg } \\
\text { (mg/kg) }\end{array}$ & $\begin{array}{c}\text { Target } \\
\text { reached? }\end{array}$ & $\begin{array}{l}\% \text { DIFF } \\
\mathrm{MD} / \mathrm{kg}\end{array}$ & $\begin{array}{l}\mathrm{L} / \mathrm{M} \\
\text { Ratio }\end{array}$ & $\begin{array}{l}\text { LD } \\
(\mathrm{mg})\end{array}$ & $\begin{array}{l}\mathrm{LD} / \mathrm{kg} \\
(\mathrm{mg} / \mathrm{kg})\end{array}$ \\
\hline 0.5 & 0.047 & 0.18 & 2.6 & 9 & 2.5 & 5.1 & 5 & Partly & $+2 \%$ & 2.2 & 5.6 & 11.2 \\
\hline I & 0.11 & 0.36 & 2.2 & 9 & 6.0 & 6.0 & 5 & No & $+20 \%$ & 2 & 12.1 & 12.1 \\
\hline 1.5 & 0.19 & 0.54 & 2.0 & 9 & 10.2 & 6.8 & 5 & No & $+36 \%$ & 1.8 & 18.3 & 12.2 \\
\hline 2 & 0.27 & 0.72 & 1.8 & 9 & 14.8 & 7.4 & 5 & No & $+48 \%$ & 1.8 & 26.7 & 13.3 \\
\hline 3 & 0.47 & 1.08 & 1.6 & 9 & 25.5 & 8.5 & 7.5 & Partly & $+13 \%$ & 1.5 & 38.3 & 12.8 \\
\hline 5 & 0.96 & 1.79 & 1.3 & 9 & 51.8 & 10.4 & 7.5 & No & $+39 \%$ & 1.3 & 67.3 & 13.5 \\
\hline 8 & 1.8 & 2.87 & I.I & 9 & 99.1 & 12.4 & 7.5 & No & $+65 \%$ & 1.3 & 128.9 & 16.1 \\
\hline 9 & 2.1 & 3.23 & 1.0 & 9 & 116.2 & 12.9 & 7.5 & No & $+72 \%$ & 1.3 & 151.0 & 16.8 \\
\hline 15 & 4.1 & 5.38 & 0.9 & 9 & 221.9 & 14.8 & 15 & Yes & $-1 \%$ & 1.3 & 288.4 & 19.2 \\
\hline 20 & 5.7 & 7.17 & 0.9 & 9 & 307.2 & 15.4 & 15 & Yes & $+3 \%$ & 1.2 & 368.7 & 18.4 \\
\hline 35 & 9.9 & 12.55 & 0.9 & 9 & 533.0 & 15.2 & 15 & Yes & $+1 \%$ & 1.2 & 639.6 & 18.3 \\
\hline 50 & 13.4 & 17.93 & 0.9 & 9 & 724.8 & 14.5 & 15 & Yes & $-3 \%$ & 1.2 & 869.8 & 17.4 \\
\hline
\end{tabular}

Both maintenance doses administered 4 times daily (MD) and loading doses (LD) are presented. For the maintenance dose expressed per $\mathrm{kg}$ (MD/kg) the difference with a standard of care dosing regimen is given.

$\mathrm{BW}$ is body weight; $\mathrm{CL}$ is the predicted clearance from final model; $\mathrm{V}$ is the predicted volume of distribution from final model; $\mathrm{t} \mathrm{I} / 2=\ln (2) /(\mathrm{CL} / \mathrm{V})$; Target $\mathrm{Cavg}$ is the target average concentration used for the model-based dosing regimen which was taken from the average steady state concentrations observed in individuals weighing 15,20,35, $50 \mathrm{~kg}$ upon the standard of care dosing regimen; $M D$ is the final model optimized maintenance dose $=\operatorname{Target} C$ avg $\times C L \times 6 \mathrm{~h}$; MD/kg is the final model optimized maintenance dose per kilogram $=\mathrm{MD} / \mathrm{BW}$; SoCMD $/ \mathrm{kg}$ is the maintenance dose per kilogram of the standard of care dosing regimen; Target Reached is the indication of whether the target concentration is reached with the standard of care doing regimen; \% DIFF MD/kg is the change of model based MD/ $\mathrm{kg}$ from the SoCMD $/ \mathrm{kg}$ in percentage $=100 \% \times(\mathrm{MD} / \mathrm{kg}$-SoCMD $/ \mathrm{kg}) / \mathrm{SocMD} / \mathrm{kg}$; L/M Ratio is the ratio of loading dose to maintenance dose in the model-based dosing regimen; $L D$ is the model-based loading dose $=M D \times L / M$ Ratio; $L D / k g$ is the final model optimized loading dose per kilogram.

The BDE function was originally developed on the basis of a very large and rich dataset from preterm neonates to adults on propofol. ${ }^{22}$ Later on, it was applied for scaling morphine across the entire human lifespan ${ }^{23}$ and in the current study on paracetamol. Concerning the results from propofol, morphine, and paracetamol from the current study, relatively similar values for $\mathrm{k}$ were found (exponent of 1.35 to $0.56,1.47$ to 0.88 , and 1.2 to 0.75 , respectively). This similarity may be explained by the fact that glucuronidation is the main pathway for these drugs upon which the question rises "whether this function could be seen as a semi-physiological function for glucuronidation in humans." For a previously developed function for morphine glucuonidation from preterm neonates to 3-year-old children, this semi-physiological function concept recently was proposed and thereafter evaluated using physiologically based modeling principles. ${ }^{34,35}$ In contrast with the similarity in ranges of exponent value $(\mathrm{k})$ across three drugs, the current function for paracetamol differed from propofol and morphine by the $\mathrm{k}_{50}$ being 12 . Two kilograms for paracetamol versus 3.78 and $4.01 \mathrm{~kg}$ for propofol and morphine, respectively, implying that paracetamol CL maturates at a slower rate than glucuronidation of propofol and morphine. A possible explanation for this finding could be that paracetamol is not entirely metabolized through glucuronidation as sulphation plays an important role, particularly in neonates. ${ }^{11}$ Therefore the current BDE model probably reflects a mixture of maturation processes with different rates for glucuronidation and sulfation.

Intravenous paracetamol is not licensed for use in children younger than 2 years of age in the United States.

Table 4. Paracetamol Clearance Across the Human Age Span: Comparison Between Previously Published Reports and the Current Study

\begin{tabular}{|c|c|c|c|c|}
\hline Year & Author & Weight & Age-span & Covariate model for clearance \\
\hline 2005 & Anderson et al ${ }^{10}$ & $0.5-55 \mathrm{~kg}$ & PCA 27 weeks -14 years & $\mathrm{CL}=16.3 \times(\mathrm{BW} / 70)^{0.75} \times(1-0.885 \times \exp (-\mathrm{PCA}$ in weeks $\times \operatorname{Ln}(2) / 26.6)$ \\
\hline 2011 & Zuppa et al" ${ }^{11}$ & Not reported & PNA 29 days-less than 18 years & $\mathrm{CL}=18.4 \times(\mathrm{BW} / 70)^{0.75} \times(\mathrm{I}-0.678 \times \exp (-\mathrm{PNA}$ in weeks $\times \operatorname{Ln}(2) / 4 \mathrm{I})$ \\
\hline \multirow[t]{2}{*}{2012} & Mohammed et al ${ }^{12}$ & $13.7-56 \mathrm{~kg}$ & $1.8-15$ years & $\mathrm{CL}=16.5 \mathrm{I} \times(\mathrm{BW} / 70)^{0.75}$ \\
\hline & This study & $0.5-94 \mathrm{~kg}$ & PCA 27 weeks-34 years & $\mathrm{CL}=17.6 \times(\mathrm{BW} / 70)^{\mathrm{k}} ; \mathrm{k}=1.204-0.454 \times \mathrm{BW}^{1.4} /\left(12.2^{1.4}+\mathrm{BW}^{1.4}\right)^{\mathrm{a}}$ \\
\hline
\end{tabular}

CL, paracetamol clearance; BW, bodyweight; PCA, postconceptional age; PNA, postnatal age.

${ }^{\mathrm{a}} \mathrm{See}$ Table 2 for parameter estimates. 
Although intravenous paracetamol is licensed in the EU for use in children of all age ranges except prematurely born neonates, there is a debate on the optimal dose for term neonates and children weighing less than $10 \mathrm{~kg}$ because higher doses than the label recommends are anticipated. $^{32}$ Current doses for preterm neonates are based on expert opinion only. ${ }^{32}$ Simulation results from our study confirmed that $15 \mathrm{mg} / \mathrm{kg}$ maintenance doses are sufficient for children with a weight between 10 and $50 \mathrm{~kg}$ (Figure 2a and b). However, a dose of $7.5 \mathrm{mg} / \mathrm{kg}$ is not enough to reach $9 \mathrm{mg} / \mathrm{L}$ average paracetamol concentration in neonates or infants weighing 5,8 , or $9 \mathrm{~kg}$. Besides, the maintenance dose of $5 \mathrm{mg} / \mathrm{kg}$ proved to be too low to reach the target concentration for a prematurely born neonate weighing $1,1.5$, or $2 \mathrm{~kg}$ (Figure 2a). Therefore, bodyweight adjusted doses were proposed for these two categories as presented in Table 3 . These doses proved to be in accordance with previous calls for adjustment of the labeled dose in infants and neonates. Palmer et $\mathrm{al}^{36}$ recommended $10 \mathrm{mg} / \mathrm{kg}$ 6-hourly for preterm neonates with postmenstrual age (PMA) of 28-32 weeks, $12.5 \mathrm{mg} /$ $\mathrm{kg}$ 6-hourly for neonates with PMA of 32-36 weeks and $15 \mathrm{mg} / \mathrm{kg}$ 6-hourly for neonates with PMA more than 36 weeks. Allegaert et $\mathrm{al}^{9}$ suggested a dosing regimen of $10 \mathrm{mg} / \mathrm{kg}$ every 6 hours within the age range 32-44 weeks PMA. Although final dose recommendations should consider not only the pharmacokinetics but also the pharmacodynamics and safety of paracetamol in neonates and infants, the current model can be the first step towards an evidence based dosing in children of all ages including preterm and term neonates. In addition, this BDE model can also be used to derive adjusted pediatric doses by use of Table 3 in which another target concentration (higher or lower than $9 \mathrm{mg} / \mathrm{L}$ ) can easily be filled in, for instance when another therapeutic target concentration for a specific age category would be identified.

\section{Conclusions}

A pharmacokinetic model for paracetamol characterizing changes in pharmacokinetic parameters across the entire human lifespan (preterm and term neonates, infants, children, and adults) was developed in which CL was found to change in a highly non-linear manner with bodyweight. The results may provide insight in the exact relation between weight and CL and as such provide a guide for individualized dosing in children. Once the therapeutic target concentration is known, corresponding appropriate doses can be easily calculated based on this model.

\section{Acknowledgments}

This study was performed within the framework of Top Institute Pharma project number D2-104. The clinical research of Karel Allegaert is supported by the Fund for Scientific Research,
Flanders (Fundamental Clinical Investigatorship 1800209N). The authors would like to thank Bristol-Myers Squibb for sharing adult data of paracetamol (Gregoire et al).

\section{Declaration of Conflicting Interests}

All authors declare no conflict of interest.

\section{References}

1. Oscier C, Bosley N, Milner Q. Paracetamol - a review of three routes of administration. Update Anaesth. 2007;23:112-114.

2. Palmer GM, Chen SP, Smith KR, Hardikar W. Introduction and audit of intravenous paracetamol at a tertiary paediatric teaching hospital. Anaesth Intensive Care. 2007;35(5):702-706.

3. Jahr JS, Lee VK. Intravenous acetaminophen. Anesthesiol Clin. 2010;28(4):619-645.

4. Hammerman C, Bin-Nun A, Markovitch E, Schimmel MS, Kaplan M, Fink D. Ductal closure with paracetamol: a surprising new approach to patent ductus arteriosus treatment. Pediatrics. 2011;128(6):e1618-e1621.

5. Yurttutan S, Oncel MY, Arayici S, et al. A different first-choice drug in the medical management of patent ductus arteriosus: oral paracetamol. J Matern Fetal Neonatal Med. 2013;26(8):825-827.

6. Allegaert K, Anderson B, Simons S, van Overmeire B. Paracetamol to induce ductus arteriosus closure: is it valid? Arch Dis Child. 2013;98(6):462-466.

7. Anderson BJ, Woollard GA, Holford NH. A model for size and age changes in the pharmacokinetics of paracetamol in neonates, infants and children. Br J Clin Pharmacol. 2000;50(2):125-134.

8. Anderson BJ, van Lingen RA, Hansen TG, Lin YC, Holford NH. Acetaminophen developmental pharmacokinetics in premature neonates and infants: a pooled population analysis. Anesthesiology. 2002;96(6):1336-1345.

9. Allegaert K, Palmer GM, Anderson BJ. The pharmacokinetics of intravenous paracetamol in neonates: size matters most. Arch Dis Child. 2011;96(6):575-580.

10. Anderson BJ, Pons G, Autret-Leca E, Allegaert K, Boccard E. Pediatric intravenous paracetamol (propacetamol) pharmacokinetics: a population analysis. Pediatr Anaesth. 2005;15(4):282-292.

11. Zuppa AF, Hammer GB, Barrett JS, et al. Safety and population pharmacokinetic analysis of intravenous acetaminophen in neonates, infants, children, and adolescents with pain or Fever. J Pediatr Pharmacol Ther. 2011;16(4):246-261.

12. Mohammed BS, Engelhardt T, Cameron GA, et al. Population pharmacokinetics of single-dose intravenous paracetamol in children. Br J Anaesth. 2012;108(5):823-829.

13. Bonate PL. The effect of collinearity on parameter estimates in nonlinear mixed effect models. Pharm Res. 1999;16(5):709-717.

14. Khandelwal A, Hooker AC, Karlsson MO. Influence of correlated covariates on predictive performance for different models. PAGE 20 (2011) Abstr 2220; 2011.

15. Allegaert K, Van der Marel CD, Debeer A, et al. Pharmacokinetics of single dose intravenous propacetamol in neonates: effect of gestational age. Arch Dis Child Fetal Neonatal Ed. 2004;89(1):F25-F28.

16. Allegaert K, Anderson BJ, Naulaers G, et al. Intravenous paracetamol (propacetamol) pharmacokinetics in term and preterm neonates. Eur J Clin Pharmacol. 2004;60(3):191-197.

17. Prins SA, Van Dijk M, Van Leeuwen $P$, et al. Pharmacokinetics and analgesic effects of intravenous propacetamol vs rectal paracetamol in children after major craniofacial surgery. Pediatr Anaesth. 2008;18(7):582-592.

18. Depre M, van Hecken A, Verbesselt R, Tjandra-Maga TB, Gerin M, de Schepper PJ. Tolerance and pharmacokinetics of propacetamol, a paracetamol formulation for intravenous use. Fundam Clin Pharmacol. 1992;6(6):259-262. 
19. Gregoire N, Hovsepian L, Gualano V, Evene E, Dufour G, Gendron A. Safety and pharmacokinetics of paracetamol following intravenous administration of $5 \mathrm{~g}$ during the first $24 \mathrm{~h}$ with a 2-g starting dose. Clin Pharmacol Ther. 2007;81(3):401-405.

20. van der Marel CD, van Lingen RA, Pluim MA, et al. Analgesic efficacy of rectal versus oral acetaminophen in children after major craniofacial surgery. Clin Pharmacol Ther. 2001;70(1):82-90.

21. van der Marel CD. Paracetamol, Widely used Hardly understood. Rotterdam: Erasmus University Medical Center; 2003.

22. Wang C, Peeters MY, Allegaert K, et al. A bodyweight-dependent allometric exponent for scaling clearance across the human life-span. Pharm Res. 2012;29(6):1570-1581.

23. Wang C, Sadhasivam S, Krekels EH, et al. Developmental changes in morphine clearance across the entire paediatric age range are best described by a bodyweight-dependent exponent model. Clin Drug Invest. 2013;33(7):523-534.

24. Bartelink IH, Boelens JJ, Bredius RG, et al. Body weight-dependent pharmacokinetics of busulfan in paediatric haematopoietic stem cell transplantation patients: towards individualized dosing. Clin Pharmacokinet. 2012;51(5):331-345.

25. Ince I, de Wildt SN, Wang C, et al. A novel maturation function for clearance of the cytochrome P450 3A substrate midazolam from preterm neonates to adults. Clin Pharmacokinet. 2013;52(7):555-565.

26. Allegaert K, Naulaers G, Vanhaesebrouck S, Anderson BJ. The paracetamol concentration-effect relation in neonates. Paediatr Anaesth. 2013;23(1):45-50.

27. Keizer RJ, Karlsson MO, Hooker A. Modeling and Simulation Workbench for NONMEM: Tutorial on Pirana, PsN, and Xpose. CPT: Pharmacomet Syst Pharmacol. 2013;2:e50.

28. Karlsson MO, Jonsson EN, Wiltse CG, Wade JR. Assumption testing in population pharmacokinetic models: illustrated with an analysis of moxonidine data from congestive heart failure patients. $J$ pharmacokinet biopharm. 1998;26(2):207-246.
29. Krekels EH, van Hasselt JG, Tibboel D, Danhof M, Knibbe CA. Systematic evaluation of the descriptive and predictive performance of paediatric morphine population models. Pharm Res. 2011;28(4): 797-811.

30. Karlsson MO, Savic RM. Diagnosing model diagnostics. Clin Pharmacol Ther. 2007;82(1):17-20.

31. Brendel K, Comets E, Laffont C, Laveille C, Mentre F. Metrics for external model evaluation with an application to the population pharmacokinetics of gliclazide. Pharm Res. 2006;23(9):20362049.

32. Paracetamol NKFK. (Perfalgan) Dutch Childrens Formularium. 2013; http://www.kinderformularium.nl/search/stof.php?id $=82$

33. Mandema JW, Verotta D, Sheiner LB. Building population pharmacokinetic-pharmacodynamic models. I. Models for covariate effects. J Pharmacokinet Biopharm. 1992;20(5):511-528.

34. Krekels EHJ, Neely M, Panoilia E, et al. From pediatric covariate model to semiphysiological function for Maturation: Part Iextrapolation of a covariate model from morphine to zidovudine. CPT: Pharmacomet Syst Pharmacol. 2012;1:e9.

35. Krekels EHJ, Johnson TN, den Hoedt SM, et al. From pediatric covariate model to semiphysiological function for maturation: Part II-sensitivity to physiological and physicochemical properties. CPT: Pharmacomet Syst Pharmacol. 2012;1:e10.

36. Palmer GM, Atkins M, Anderson BJ, et al. I.V. acetaminophen pharmacokinetics in neonates after multiple doses. Br J Anaesth. 2008;101(4):523-530.

\section{Supporting Information}

Additional supporting information may be found in the online version of this article at the publisher's web-site. 